\title{
Detection Of Aortic Valve Stenosis Using A Convolutional Neural Network
}

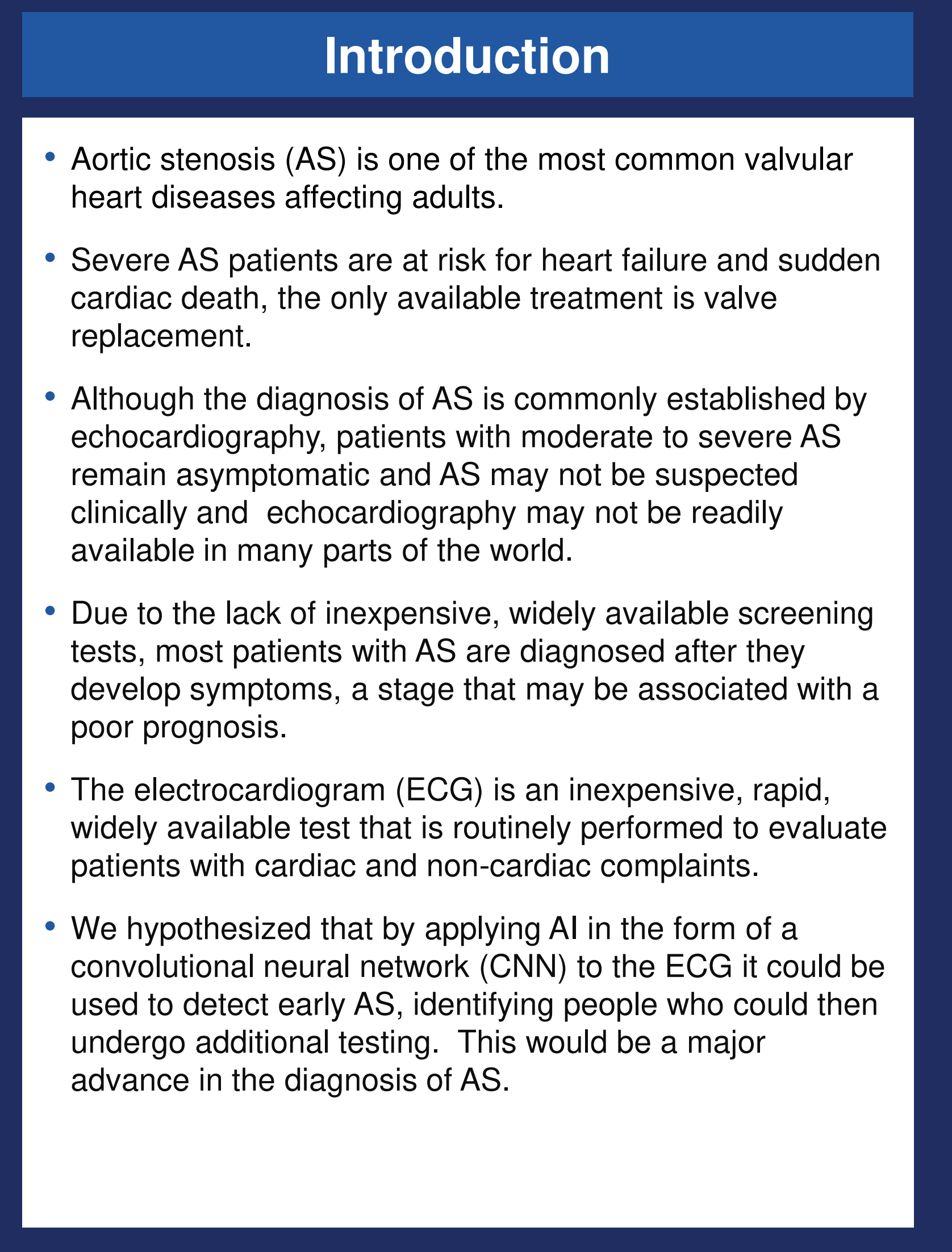

Objective

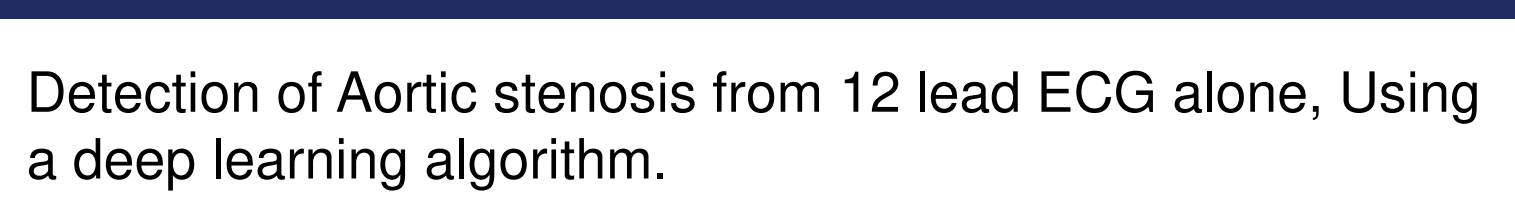

Figure 1 - AS pathophysiological mechanism

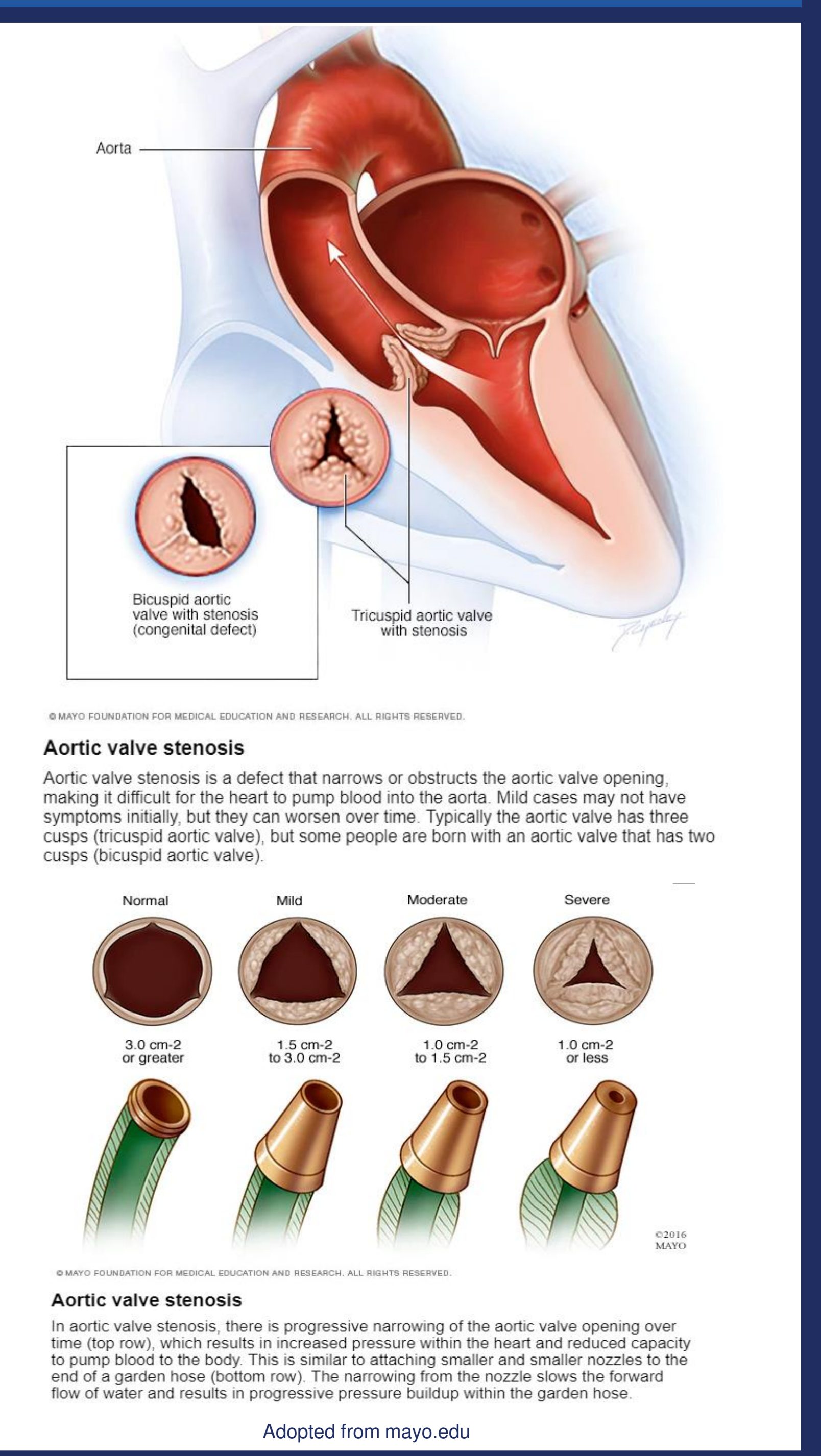

Methods

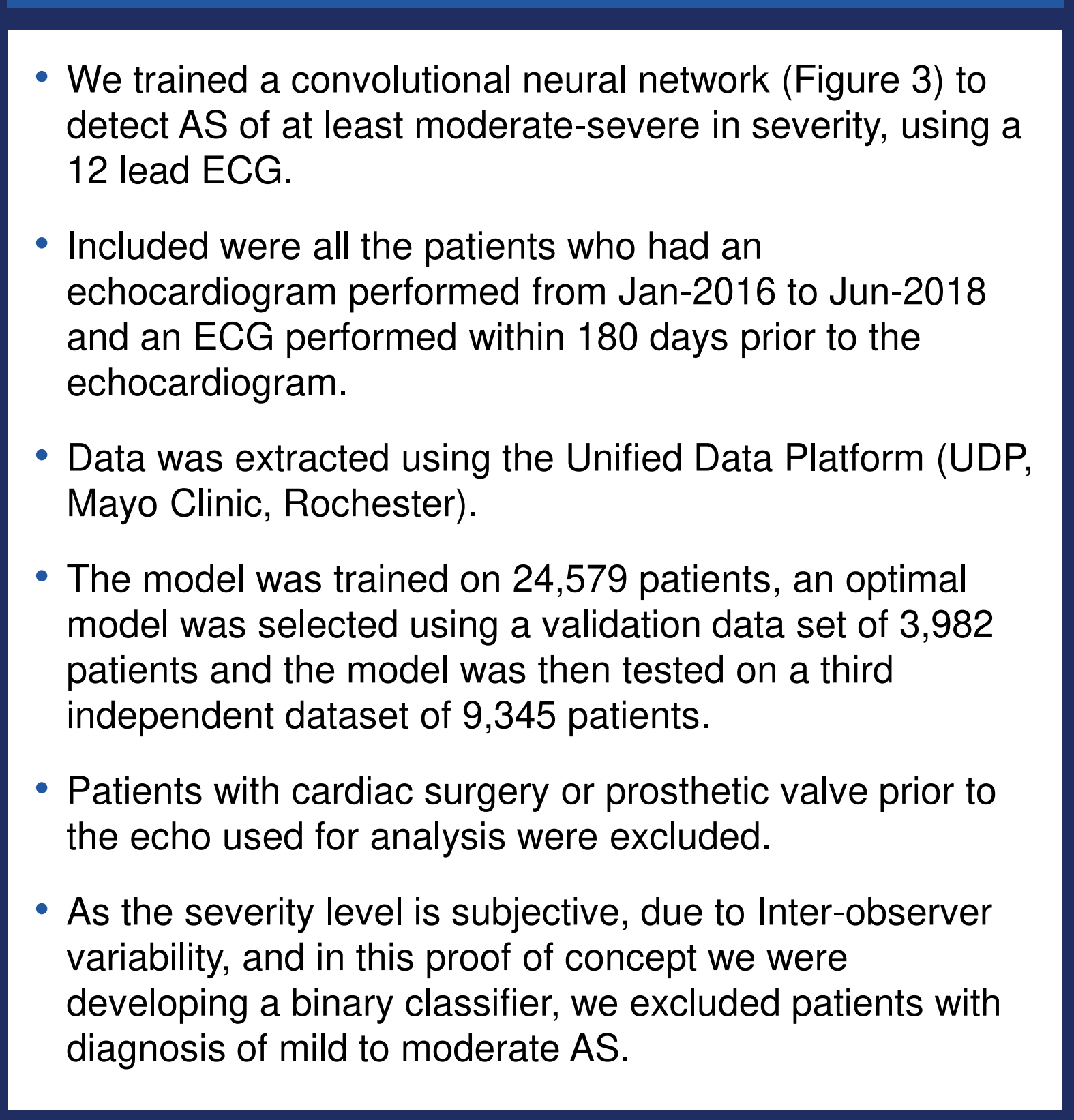

Figure 2 - Cohort selection

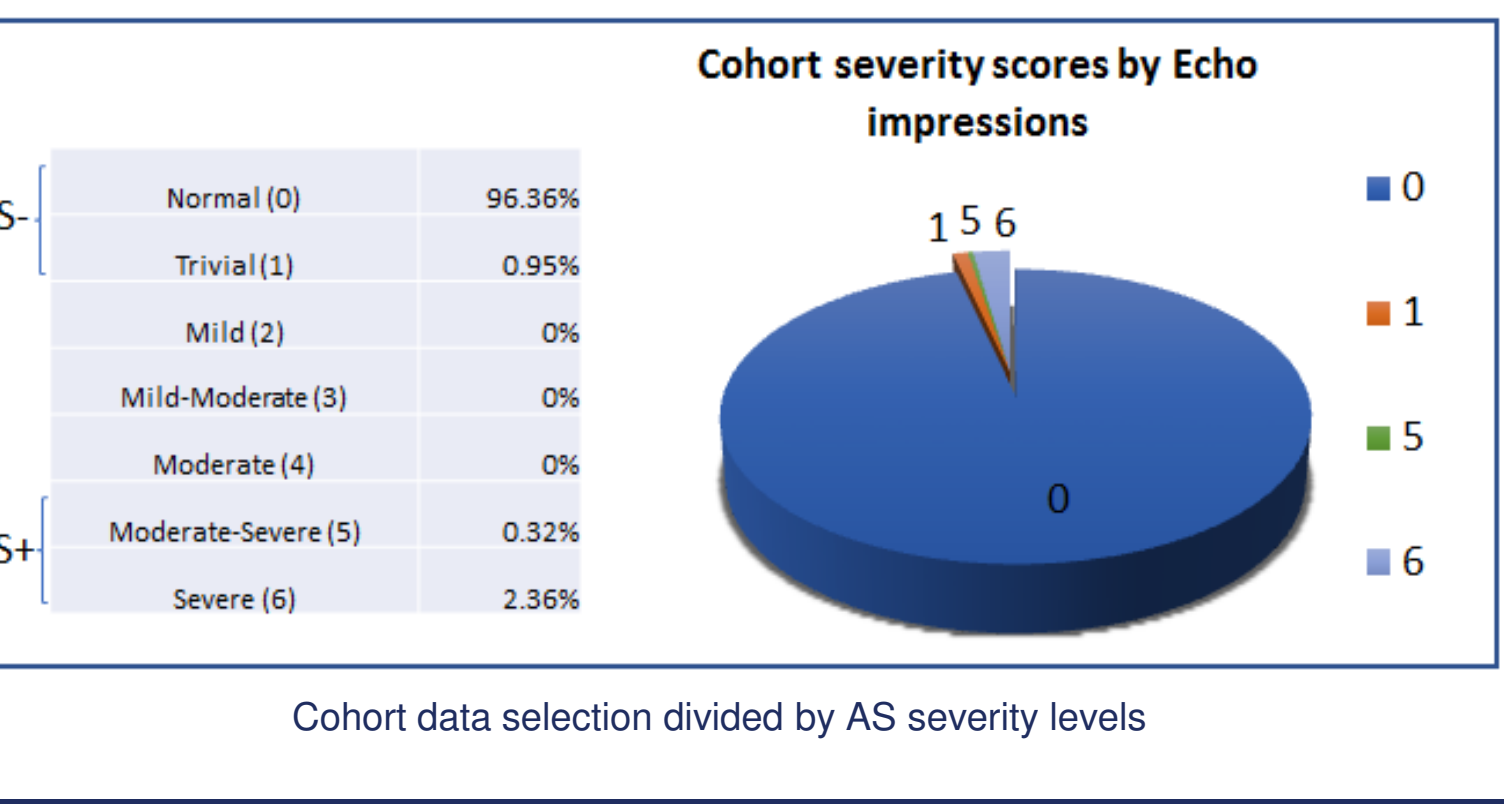

Figure 3 - CNN Architecture

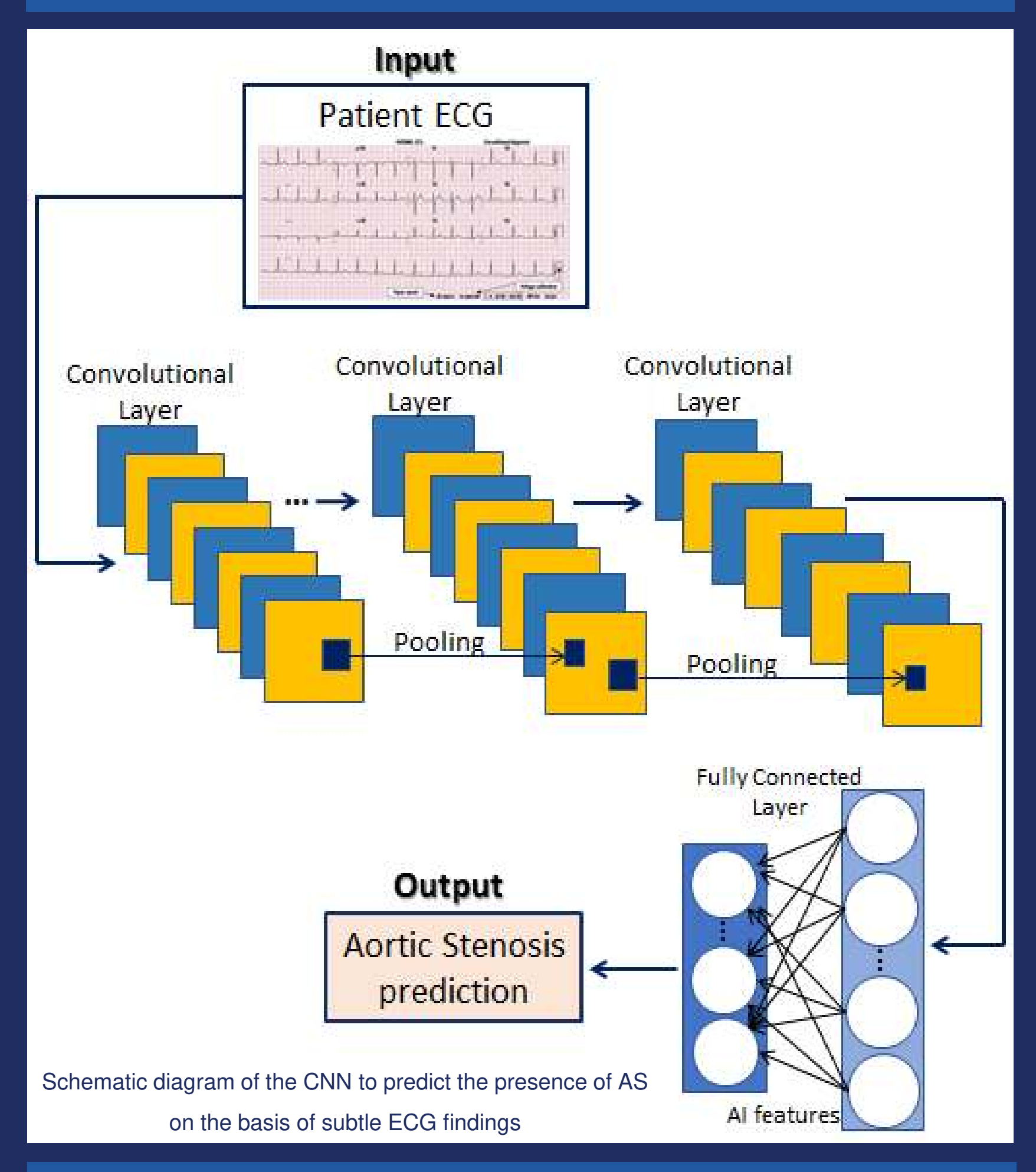

Results

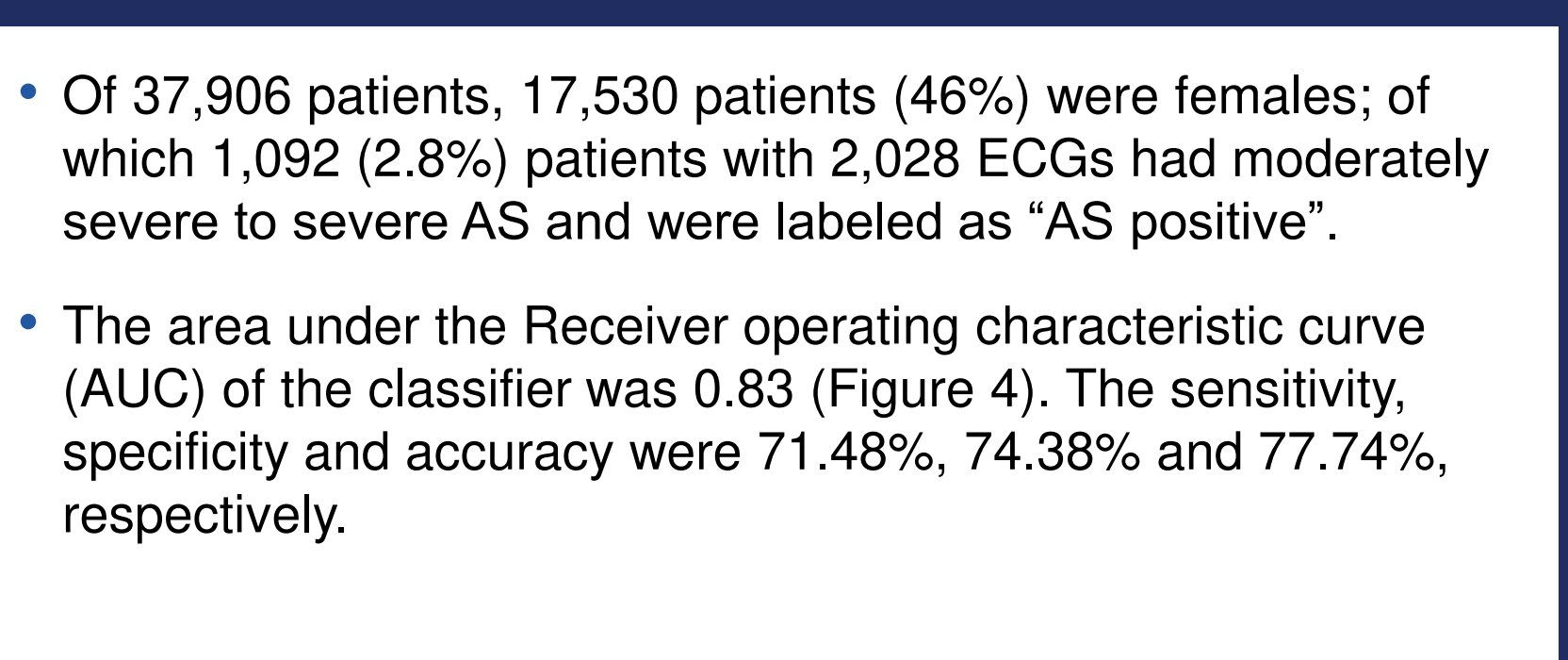

Figure 4 - AUC results $\underset{10}{R}$ Receiver Operating Characteristic

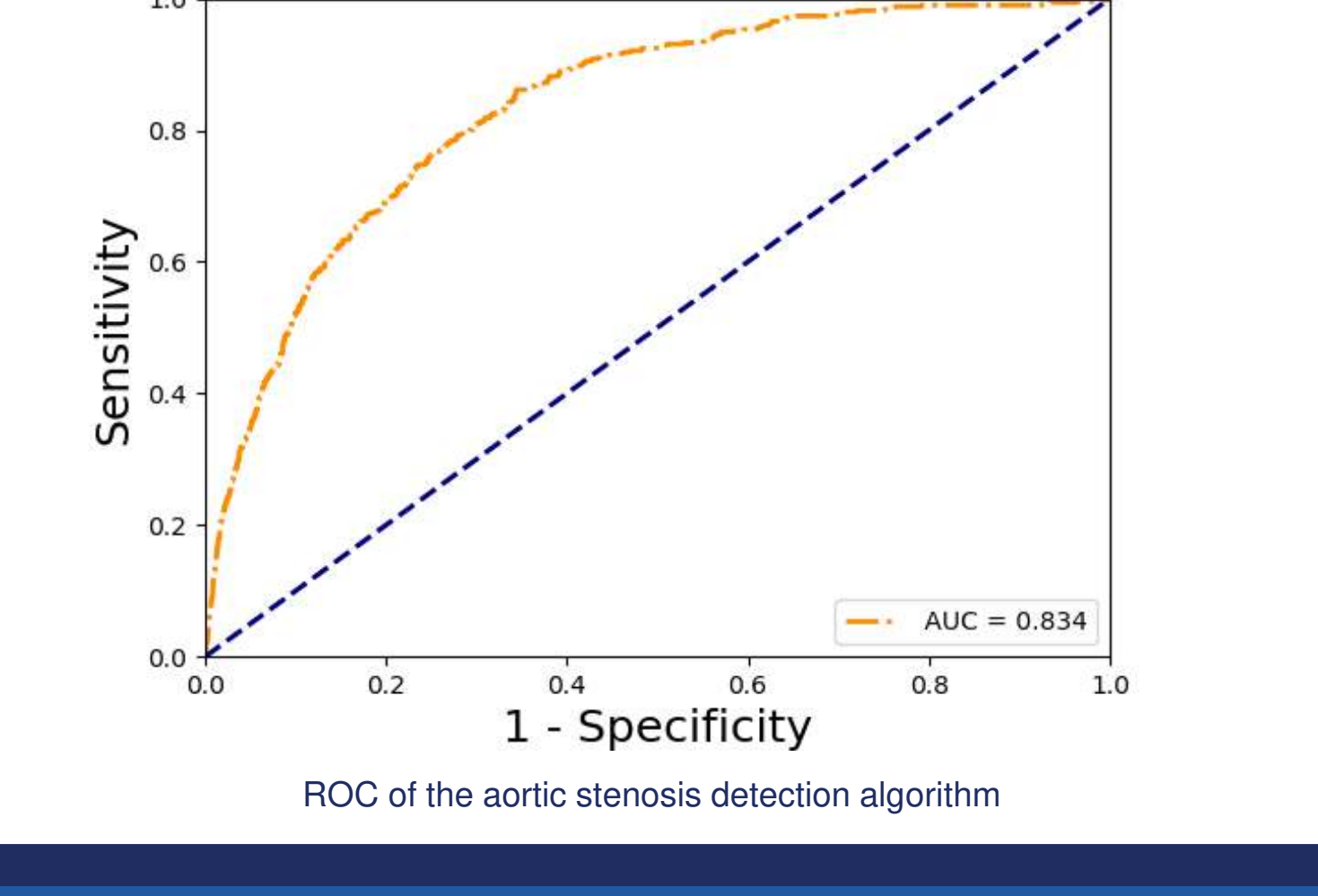

Conclusion

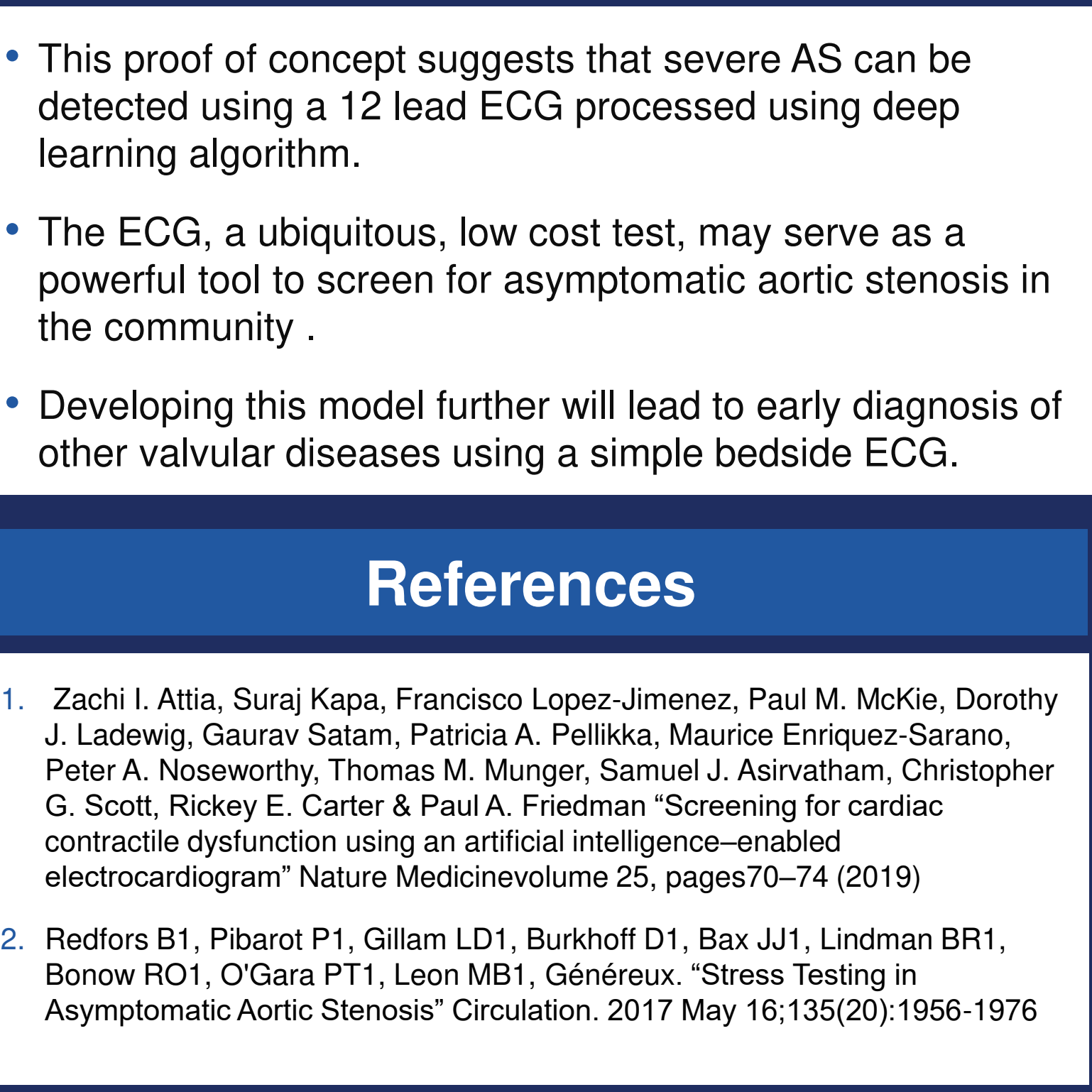

